\title{
Synthetic seismograms and spectral cycles on the Andvord and Schollaert Drifts: Antarctic Peninsula
}

\author{
P. L. Manley ${ }^{1}$ and S. Brachfeld ${ }^{2}$ \\ ${ }^{1}$ Geology Department, Middlebury College, Middlebury, VT 05753 (manley@middlebury.edu) \\ ${ }^{2}$ Department of Earth \& Environmental Studies, Montclair State University, Upper Montclair, NJ 07043 (brachfelds@mail.montclair.edu)
}

Abstract The geological significance of seismic reflectors within large sediment deposits of the Gerlache Strait (Schollaert Drift) and the mouth of Andvord Bay (Andvord Drift) has been examined using synthetic seismograms. The seismograms generated from the physical properties in jumbo piston cores taken at each of these drifts (28JPC and 18JPC respectively) show good agreement with the field seismic profiles when core disturbance is taken into consideration. Both cores suggest an under-sampling of up to $30 \%$ (or compaction) during coring. This leads to inaccuracy in the evaluation of past sedimentation rates and thus interpretations on these rates may be biased.

Citation: Manley, P. L. and S. Brachfeld (2007), Synthetic seismograms and spectral cycles on the Andvord and Schollaert Drifts: Antarctic Peninsula, in Antarctica: A Keystone in a Changing World - Online Proceedings of the 10th ISAES, edited by A. K. Cooper and C. R. Raymond et al., USGS Open-File Report 2007-1047, Short Research Paper 018, 5 p.; doi:10.3133/of2007-1047.srp018.

\section{Location and Methods}

High-resolution seismic profiling (Bathy 2000 $3.5 \mathrm{kHz}$ Chirp) has identified large sediment deposits within the Gerlache Strait (Schollaert Drift, Canals et al., 1998) and the mouth of Andvord Bay (Andvord Drift, Harris et al., 1999) in Antarctic Peninsula. Jumbo piston cores were taken at each of these drifts (28JPC and 18JPC respectively) during cruise 99-03 of the U.S. Antarctic Program Research Vessel Nathaniel B. Palmer (Domack et al. 2003) (Figure 1).

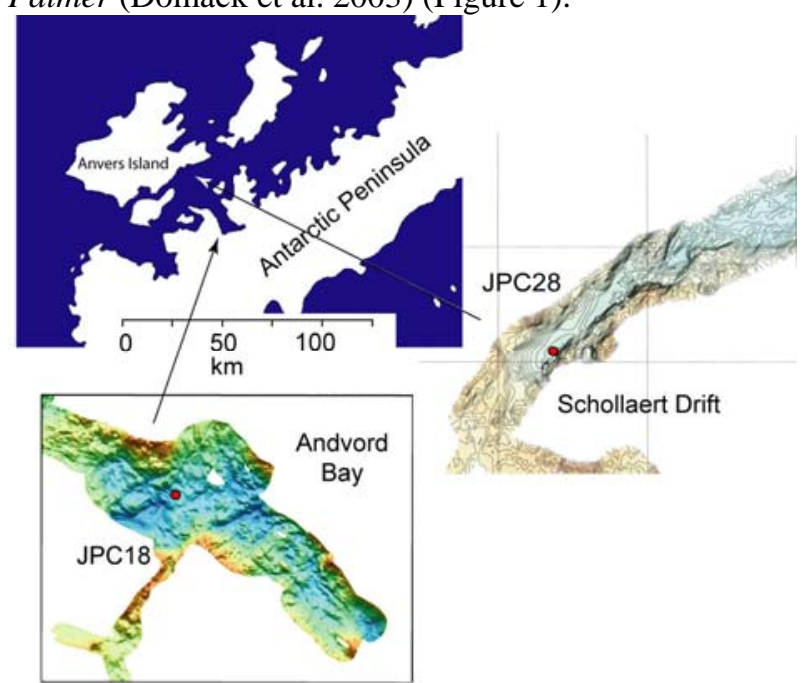

Figure 1. Location map in the Antarctic Peninsula with swath map bathymetry from NB9803 and NBP9902 cruises showing core locations on the two drifts.

Compressional-wave velocities and magnetic susceptibility $(\mathrm{k})$ were measured at 2-5 cm intervals on linered whole cores using a manually operated p-wave logger and Bartington MS2C 125-mm diameter sensor upon core retrieval. A second set of physical property measurements were performed at the Antarctic Research Facility, Florida State University, immediately after the cores were split open. These include gamma-ray attenuation porosity evaluation (GRAPE bulk density), electrical resistivity (ER), and index properties.
Saturated bulk densities were calculated from the water content of $\sim 5$ cc sediment samples taken at the location of $\mathrm{Vp}$ measurements. Other physical properties such as porosity, water content, and void ratio were derived from the wet and dry $\left(24\right.$ hours at $\left.100{ }^{\circ} \mathrm{C}\right)$ discrete sample weights. Quantitative diatom studies, percent biogenic silica and quantitative XRD analyses of mineral content were subsequently completed for 28JPC.

Uncorrected radiocarbon ages from Domack et al. (2003) were corrected using a reservoir age of 1200 years (Kirkwood et al., 2004). Corrected radiocarbon ages were converted to calendar ages using the INTCAL98 radiocarbon calibration program version 4.2 of Stuiver et al. (1998). Both least squares lines and polynomial curve fits were calculated for the depth-age data in order to construct age models for 18JPC and 28JPC.

Spectral analysis of down-core time series data was performed using the Blackman-Tukey routine available in Analyseries software (Paillard et al., 1996). Each dataset was re-sampled at a constant time step of 10-20 years, depending on the spatial sampling interval of the proxy and the age model applied. For each time series we used a number of lags equal to $30 \%$ of the length of the series, and evaluated statistical significance at the $80 \%$ confidence level. Spectral analysis was performed over 3 time intervals: (1) the entire series, 160 to $\sim 6500$ yrs B.P. for 18JPC and 0 to 4100 yrs B.P. for 28JPC, (2) 0 to 2800 yrs B.P., and (3) 2800 yrs. B.P. to the base of the core. This approach was chosen due to the large shift in the dynamic range of $\mathrm{k}$ at $\sim 2800-3000$ yrs B.P. For consistency, we also evaluated the biogenic silica time series over these same 3 intervals. We have the most confidence in spectral peaks that are present in more than one proxy, and which are present regardless of the age model applied.

\section{Synthetic Seismogram}

To generate a synthetic seismogram the seismic source signature and the reflection coefficient log of the core are needed. Sediment properties are measured as a 
function of depth in the core whereas the seismic profile is a function of time. To accurately transform core depth to travel-times the downcore in-situ velocity is needed. There is no downcore logging at these sites, however pwave velocities measured on the linered cores, can be corrected to in-situ velocity values. Hamilton (1965, 1976) shows that four corrections need to be applied to laboratory measured properties to get approximately insitu values; volume rebound, temperature difference, decrease in hydrostatic pressure, and release of intergranular pressure (decrease in rigidity). Since these cores are less than $20 \mathrm{~m}$ in length, corrections for temperature difference (ocean floor values to ambient temperatures) and hydrostatic pressure need only be applied. The final corrected p-wave velocity does not have a correction for rigidity applied to it. Using the corrected p- wave velocity, the density data depths are converted to a travel-time (sec) and then an impedance profile was generated and resampled at $0.1 \mathrm{~ms}$ intervals, based on corrected p-wave velocity $(v)$ times density $(\rho)$ :

$$
\mathrm{I}=v \rho
$$

The impedance profile is used to compute the reflection coefficient $\log$ (R.C.). The reflection coefficient log is computed by comparing impedances (I) downcore given by

$$
\text { R.C. }=I_{2}-I_{1} /\left(I_{2}+I_{1}\right)
$$

where R.C. would be the impedance contrast in downcore positions 1 and 2. Convolving the reflection coefficient $\log$ with a source signature generates the synthetic seismogram (Figure 2). Convolution is defined as the integral of the product of two functions (reflection coefficient log and source signature in this case) after one is reversed and shifted; written as:

$$
(f * g)(t)=\int f(\tau) g(t-\tau) d \tau
$$

\section{FORWARD MODELING}

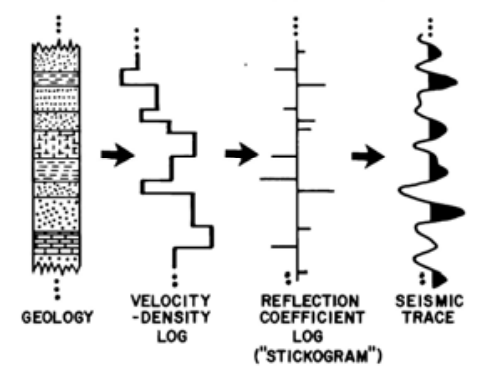

Figure 2. Cartoon depicting the steps for generating a synthetic seismogram

\section{Synthetic seismogram correlation to Bathy 2000}

Large diameter cores from the North Atlantic (e.g. Manley et al., 2004) show "stretching" or over-sampling of the upper 6-10 meters of the recovered JPCs. Work by Széréméta et al (2004) and Skinner and McCave, (2003) have shown that large diameter piston cores (JPC) are subjected to sediment thinning (under-sampling) or thickening (over-sampling) (Figure 3). As a result of either sediment thinning and/or thickening from coring disturbances, subsequent calculated sedimentation rates can be affected. We investigated whether sediment thinning or thickening occurred for the Antarctic drift cores by generating synthetic seismograms and comparing them to the seismic profiles.

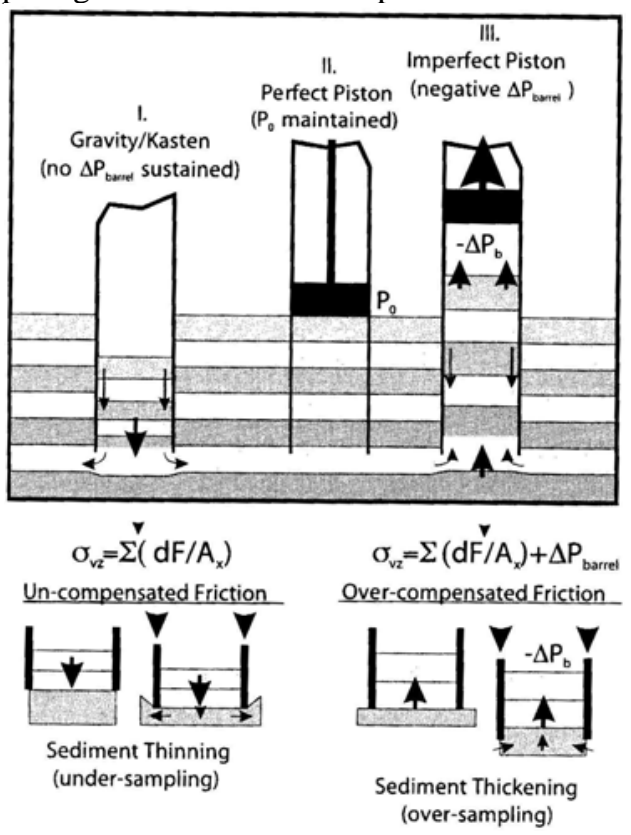

Figure 3. From Skinner and McCave (2003) showing the effects of under- and over-sampling with large diameter piston cores (JPCs)

A Bathy 2000 source was convolved with the reflection coefficient (determined from the core) to generate the synthetic seismogram. This was then superimposed on the Bathy 2000 (Chirp $3.5 \mathrm{kHz}$ ) record for comparison. Lithologic logs (Domack et al., 2003) for both sites were also placed on the record (Figures 4 and 5). For each core the correlation of $3.5 \mathrm{kHz}$ reflectors and the uncorrected synthetic seismogram is not a good match. Panel B shows the same $3.5 \mathrm{kHz}$ profile, core depth, but the lithologic column and synthetic are linearly "stretched" to match prominent reflectors. This "stretching" is to compensate for compaction occurring in the coring process. For both cores a compaction of about $30 \%$ was determined as a uniform compaction was used. Though the "stretched" synthetic seismogram's match is much better with this 30\% uniform compaction, there are specific sections where non-linear stretching would provide the best possible correlation (see arrow on Figure 5).

\section{Origin of reflectors}

What causes the change in impedance and is therefore the origin of the reflectors? Mayer (1979) showed that density was the dominant control on impedance and the source of reflectors. Additional work 


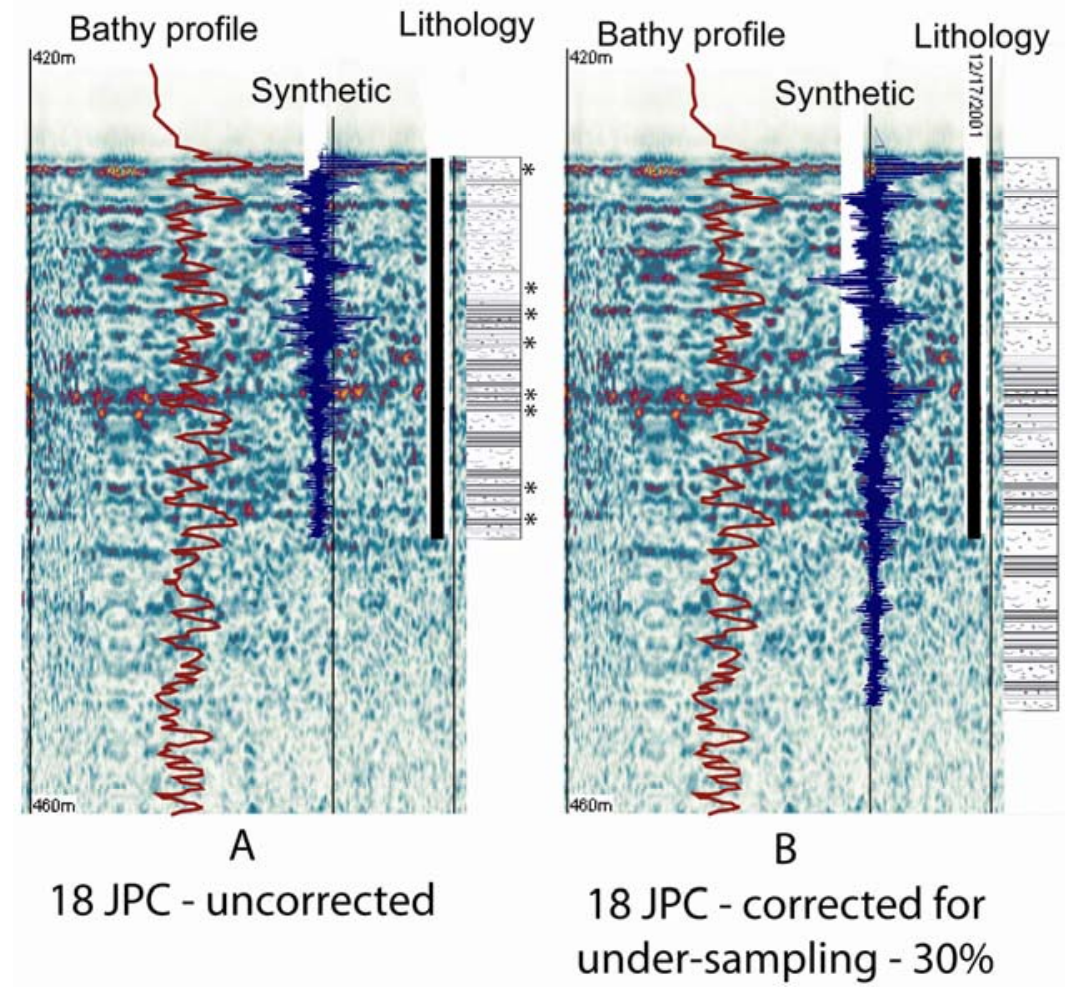

Figure 4. Synthetic seismograms (blue) for 18JPC uncorrected and corrected for 30\% compaction overlain on Bathy 2000 Chirp sonar record. An individual Bathy trace is shown in red for the core site. Core depth is shown by the black line along with core lithology. Asterisks show location of uncorrected radiocarbon ages.

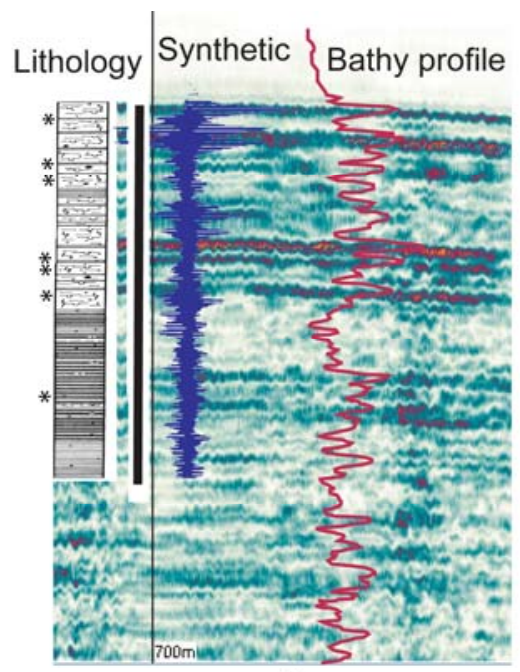

A

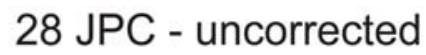

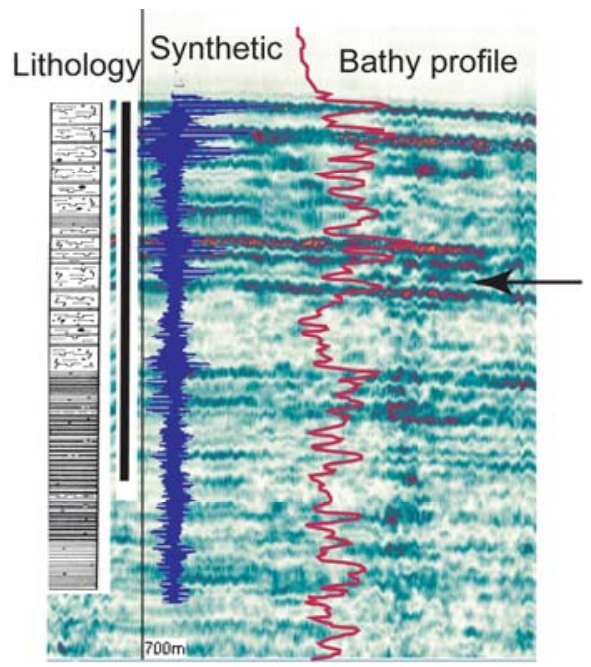

B

\section{JPC - corrected for under-sampling (30\%)}

Figure 5. Synthetic seismograms for 28JPC uncorrected and corrected for 30\% compaction overlain on Bathy 2000 Chirp sonar record. An individual Bathy trace is shown in red for the core site. Core depth is shown by black line with along with core lithology. Asterisks show location of uncorrected radiocarbon ages.

by Mayer et al. (1986) and Slowey et al. (1989) demonstrated the control that carbonate content has on density and reflectors. Impedance is dependent on the combination of p-wave velocity (Vp) and density (Eq.
1). By plotting density versus impedance and density versus $\mathrm{Vp}$, and looking at the correlation coefficients, it is apparent that density is the predominant control of impedance in both 18JPC and 28JPC (high $\mathrm{R}^{2}$ of 0.88 
and 0.99 respectively). What controls density? Plots of density versus various physical parameters show that for the lower section of 28JPC, biogenic silica is the dominant control $\left(\mathrm{R}^{2}=0.71\right)$. As with 28JPC, density is the dominant control for 18JPC.

\section{Spectral analyses}

Using the raw core depths we observed several "pseudo-significant" peaks in the power spectra of both 18JPC and 28JPC when the full time series is evaluated We use the term pseudo-significant to describe peaks in spectral power that match periodicities observed elsewhere along the Antarctic margin (e.g., Leventer et al., 1996; Domack et al., 2003; Dunbar et al., 2000, 2001) and whose peak power exceeds the upper confidence spectra of adjacent troughs. These include periods of 160-200 years, 90 years, 80 years, and $\sim 65-70$ years in the $\mathrm{k}$, biogenic silica, and impedance time series. These results are consistent with those obtained by Kirkwood et al., 2004, who evaluated time series from these cores using the Maximum Entropy Method. In general, the spectra derived from the middle Holocene intervals (2800 to 4100 yr B.P. or 3000 to 6500 yr B.P.) are featureless. This could be a function of highly variable sedimentation rates, which we cannot, at present, adequately constrain with our distribution of radiocarbon dates or genuine non stationarity of the signal in this particular depositional system. For peaks to be considered truly statistically significant, the value of the lower confidence spectrum of the peak should exceed the value of the upper confidence spectrum of the adjacent troughs. This occurs only in core 28JPC for the broad band of periodicities in the range of 160 to 174 years. This feature is present in both the linear and polynomial age models, and is resolved in the $\mathrm{k}$, biogenic silica, and impedance datasets.

We then repeated spectral analysis routines using the depth-corrected age model, obtained by correlating the synthetic seismogram with the Bathy $20003.5 \mathrm{kHz}$ Chirp profile. A relationship derived between original depth and corrected depth indicates a nearly uniform $30 \%$ compaction down the core. Since the compaction is uniformly distributed, there is no significant change in the periodicities obtained via spectral analysis. Wavelet analysis was then applied using the online Interactive Wavelets software available at ion.researchsystems.com. Wavelet analysis allows us to identify the specific time intervals when periodicities are present or absent. In contrast, spectral analysis solves for periodicities using the entire input time series, without the ability to detect when, or if, these periodicities come and go through time (non stationary).

We observe some power in the multidecadal to centennial frequency bands during the late Holocene for the impedance and magnetic susceptibility time series of 28JPC, but no significant features prior to $2.5 \mathrm{ka}$ (Figure 6 ). The 28JPC biogenic silica time series shows power in the multidecadal to centennial bands from 3-4 ka (Figure 7). These discrepancies could be due to several factors. There is a large drop in amplitude of magnetic susceptibility in the lower half of both 18JPC and 28JPC, which dampens the susceptibility cycles. The lower half of both 18JPC and 28JPC are characterized by alternations in sediment texture between massive and laminated intervals. The available radiocarbon dates may not be sufficient to capture the changes in the sedimentation rate below the middle Holocene to late Holocene transition.

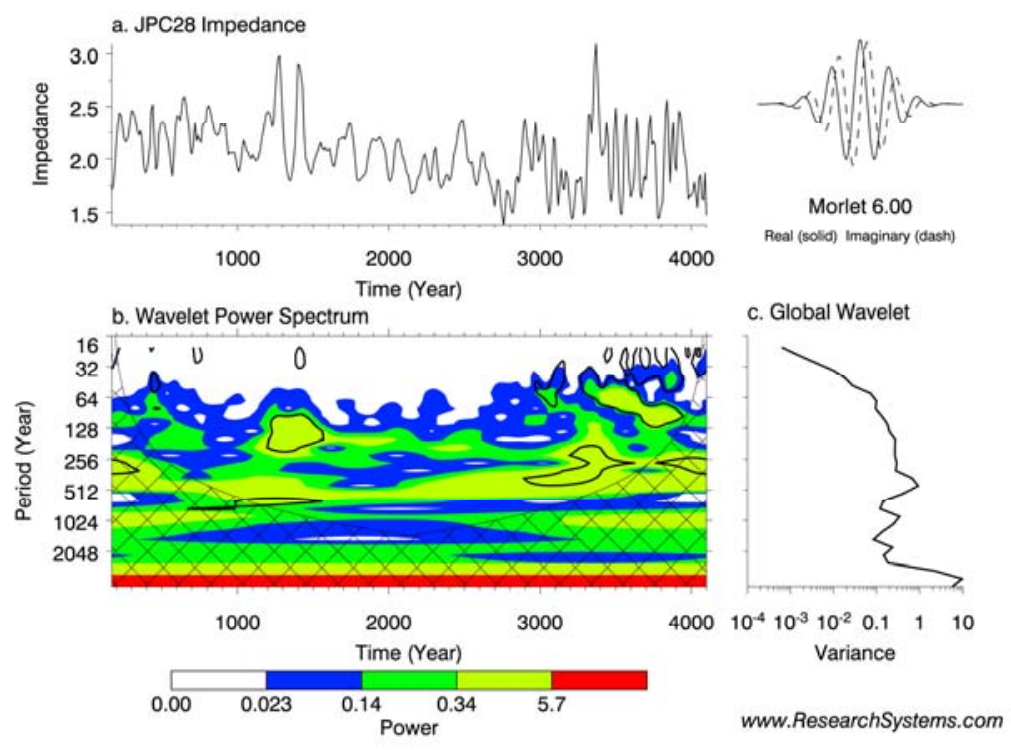

Figure 6. Wavelet analysis on impedance for 28JPC. 


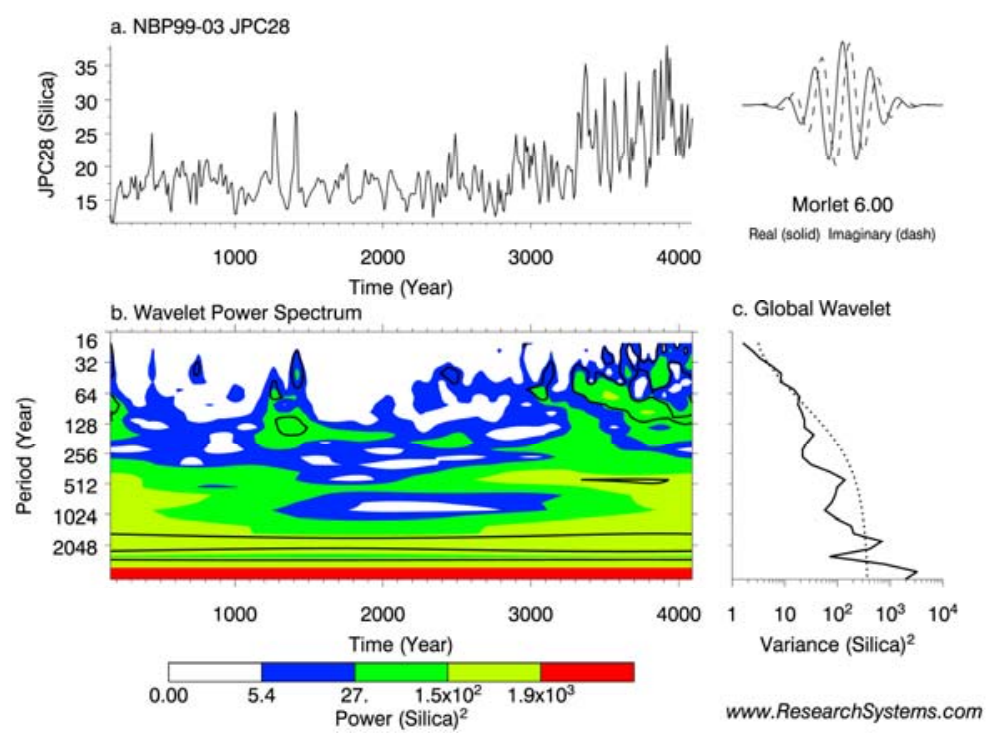

Figure 7. Wavelet analysis on biogenic silica for 28JPC.

\section{Implications}

1. Synthetic seismograms allow for determining the true depth of core penetration and possible core distortion. The best fit of the synthetic seismograms suggests that 28JPC and 18JPC have been under-sampled (compacted) during the coring process. Estimates suggest at least $30 \%$ compaction. This is likely due to the high water content found within these cores that increases with depth.

2. Core distortions, if not accounted for, can lead to errors in age-depth relationships, sedimentation rates and calculated mass fluxes.

3. Time series analysis on distorted cores may also be skewed if there is a differential amount of compaction down core. In this study, we observed no significant changes in the results of spectral analysis when the compaction was uniform down core.

Acknowledgements. We thank the captain and crew of the N.B. Palmer as well as Matt Curran and Tom Janacek of the Antarctic Research Facility for assisting with the cores. We wish to thank Peter Harris and Will Howard for their helpful reviews of this manuscript as well as Howard Stagg. This work was supported by NSF OPP9615670 to Patricia Manley.

\section{References}

Canals, M., F. Estrada, R.Urgeles, GEBRAP 96/97 Team (1998), Very high-resolution seismic definition of glacial and postglacial sediment bodies in the continental shelves of northern Trinity Peninsula region, Antarctica, Annals of Glaciology, 27, 260-264.

Domack, E.W., A. Leventer, S. Root, J. Ring, E. Williams, D. Carlson, E. Hirshorn,W. Wright, R. Gilbert, and G. Burr (2003), Marine sedimentary record of natural environmental variability and recent warming in the Antarctic Peninsula, Antarctic Research Series, 79, 205-224.

Dunbar, R. B., A. C. Ravelo, E. W. Domack, A. Leventer, and S. Brachfeld (2001), 13,000 years of decadal-to-millennial oceanographic variability along the Antarctic Peninsula: ODP Site 1098, in International ANTOSTRAT Symposium, Geologic Record of the Antarctic Ice Sheet from Drilling, Coring, and Seismic Studies, edited by Florindo, F. and A. Cooper, 59.
Dunbar, R. B., A. C. Ravelo, E. Domack, A. Leventer, L. Anderson, D. A. Mucciarone, and S. Brachfeld (2000), 13,000 Years of Decadalto-Millennial Oceanographic Variability Along the Antarctic Peninsula, ODP Site 1098, EOS Trans. AGU, 95, OS51B-8.

Hamilton, E. L. (1965), Sound speed and related physical properties of sediments from Experimental Mohole (Guadalupe Site), Geophysics, 30, 257-300.

Hamilton, E. L. (1976), Variations of density and porosity with depth in deep-sea sediments, J. Sediment. Petrol., 46, 280-300.

Harris P., E. Domack, P. L. Manley, R. Gilbert and A. Leventer (1999), The Andvord Drift: A New Type of Glacial Marine Deposystem from the Coastal Regime of the Antarctic Peninsula, Geology, 27, 683-686.

Kirkwood, G., E. Domack, S. Brachfeld, C. Escutia (2004), Solar vs. Tidal Forcing of Centennial to Decadal Scale Variability in Marine Sedimentary Records from the Western Antarctic Peninsula, EOS Trans. AGU, 80, 526.

Leventer, A., E. Domack, S. E. Ishman, S. Brachfeld, C. McClennen, P. L. Manley (1996), Productivity cycles of 200-300 years in the Antarctic Peninsula region: Understanding linkages among the sun, atmosphere, oceans, sea ice, and biota, GSA Bulletin, 108, 16261644.

Manley, P. L., T. O. Manley, L. Kelly, J. Wright, and G. Mountain (2004), Mudwaves on the South Gardar Drift: North Atlantic, EOS Trans. AGU, Jt. Assembly Suppl. Abstract GC21A-05.

Mayer, L. A. (1979), Deep-sea carbonates: acoustic, physical, and stratigraphic properties, Journal of Sed. Pet., 49, 819-836.

Mayer, L. A., T.H. Shipley and E.L. Winterer (1986), Equatorial Pacific Seismic Reflectors as Indicators of Global Oceanographic Events, Science, 233, 761-764.

Paillard D., L. Labeyrie, and P. Yiou (1996), Macintosh Program Performs Time-Series Analysis, EOS Trans. AGU, 77, 379.

Skinner, L. C. and I. McCave (2003), Analysis and modeling of gravity- and piston coring based on soil mechanics, Mar.Geol., 199, 181-204.

Slowey, N. C., A. C. Neumann and K. C. Baldwin, (1989), Seismic expression of Quaternary climatic cycles in the peri-platform carbonate ooze of the northern Bahamas, GSA Bulletin, 101, 15631573.

Stuiver, M., P. Reimer, B. Bard, J. W. Beck, G. S. Burr, K. A. Hughen, B. Kromer, G. McCormac, J. Van Der Plicht, and M. Spurk (1998), INTCAL98 radiocarbon age calibration 24,000-0 cal. BP, Radiocarbon, 40, 1041-1083.

Széréméta, N., F. Bassinot, Y. Balut, L. Labeyrie, and M. Pagel (2004), Oversampling of sedimentary series collected by giant piston corer: Evidence and corrections based on $3.5 \mathrm{kHz}$ chirp profiles, Paleoceanography, 19, PA1005. 